\title{
TARGETING DEVELOPMENT OF THE SPECIFIC CONDITIONAL QUALITIES OF THE BASKETBALL STUDENTS
}

\author{
I. Peltekova* \\ Department of Sport, Sofia University, St. Kliment Ohridski”, Sofia, Bulgaria
}

\begin{abstract}
This report is provoked by the specific work with students from Sofia University "St. Kliment Ohridski". The contingent of the study was 77 students (men and women) who chose to practice basketball in group-educated groups at the University. The report is based on the results of conducted sport-pedagogic testing that was made on field conditions. In order to determine the level of the specific conditional qualities of the students it was used the international test battery "SPARQ", specialized for basketball players. The test battery contains eight tests: fastness, upper limb force, explosive force, strength endurance, flexibility, agility in basketball defense movement.

The aim of the study is to provide information on changes in the level of the specific conditional qualities of the basketball students as a result of specialized training. The results of the study are subject to mathematical and statistical processing under SPSS - 19. The ANOVA dispersion analysis was used to test the hypothesis for comparing three or more Fisher F-criteria samples.

The analysis of the result confirms that there was a significant change in the groups and a significant difference between them, with better values of the experimental groups.
\end{abstract}

Key words: sport, basketball preparation, physical qualities, methodology, methods and means

\section{INTRODUCTION}

The basketball game as a tool for physical education and sport is widely used in the structure of sports activities. Basketball is one of the most popular ball games in the world. The game is accessible, understandable, dynamic. Systemic basketball or game play helps physically, mentally and emotionally develop people.

Physical qualities as a human manifestation, performing sports activities, constitute a single set of specific movements that are relatively independent and characteristic of each individual sport.

The concept of conditioning qualities has become a must in sports literature in recent years. The term "physical condition" is used to mean a physical state that reflects the level of development of the following components:

\footnotetext{
*Correspondence to: Iren Peltekova, PhD; Department of sport, Team sports and mountain sports, Sofia University, address: bul. "Tsar Osvoboditel” 15, 1504 Sofia, Bulgaria, email:iren.peltekova@gmail.com, telephone: $+359 / 887511468$
}

736 speed, strength, endurance, flexibility and body composition. The term "condition" (Physical Fitness) reflects the degree of adaptation of the body to physical exercise and is characterized by three main components - the state of health, physical development and physical employability of the individual.

The training exercises directed at the individual sides of the training (technical, tactical, physical, psychological) must be optimal in order to reach the desired top sporting form. Conditioning training is closely related to basketball play. Successful use of technical skills is dependent on the level of physical qualities and vice versa.

In today's basketball, the presence of a conditioning specialist in the team is a must. Success in basketball play can only be achieved when basketball coaches and conditioning specialists work together with a single program and enjoy mutual trust.

In the scientific forums, research and author's research on conditional condition of university students are becoming more important. 
According to the authors, in order to practice the chosen profession successfully, specific psychic and motor skills and personal characteristics, for students of different specialties are needed.

Many teachers of physical education and sport in universities in Bulgaria use the tools of the basketball game to improve the condition and the health of the students. In their research, T. Simeonova, Y. Bancheva, P. Klechkov (2012) aim to reveal the physical education of students involved in physical education and sport at three universities, who have been chosen for their sports activities basketball.

On this basis, they make a comparative analysis of the level of basic motor skills that the basketball game develops. They reveal that "in terms of physical training in tests containing elements of basketball game, students from the University of Shumen, the Technical University of Varna and the Southwest University show similar results (speed, endurance, agility) and various opportunities for jump" (1).

The success rate of training in all sports activities depends both on the number of activities and on the sporting experience. This is confirmed by the research done on the physical capability of students from the basketball groups and students from the representative basketball teams of UNWE.

With more sporting activities a week and with more sporting experience, the results are always better. (2-3). The same dependence was established by G. Ignatov (2016) in the study of the momentary physical condition of the students from the representative football team of Sofia University "St. Kliment Ohridski" which stated that the four students who are best prepared conduct a training and competition process with both the student team and the football clubs from the amateur "B" groups of the Republic of Bulgaria (4).

In a study G. Ignatov and E. Atanasov (2017) determine the momentary physical condition of the students from the representative football teams of NSA "Vassil Levski" and Sofia University "St. Kliment Ohridski "using the" IRST "test. The results show that the students from the NSA "Vasil Levski" are better physically prepared than those from the Sofia University. The authors explain these results with the majority of practical exercises in the curriculum of NSA students, which help to increase their conditional opportunities (5).
Scientific interest in the variability of the physical qualities and the morpho-functional indicators of the students are also shown by the sports specialists from MU and TU (6). The development of students' specific conditioning qualities represents a wide field of research and has a rich tradition.

Today, these problems are of increasing interest and are constantly growing (7). The physical qualities and morpho-functional indicators of the young people from different specialties in VU are manifested in different variability and are a prerequisite for good future professional realization (8).

A number of authors link the improvement of speed-strength qualities to a specific training methodology that focuses both on the type of sport and on gender and age of practitioners (911).

\section{METHODOLOGY}

The aim of the present study is to reveal the effect of a purposeful application of a experimental methodology to develop conditional qualities

The object of the study is the basketball preparation of the students.

The subject of the study is the specific conditioning training of students practicing basketball.

Methods: Seven types of measurements were made to determine the level of specific conditioning training for basketball students. A SPARQ test battery for basketball players (Speed; Power; Agility; Reaction; Quickness) has been used (Table 1). The test is designed to measure specific athleticism. The test coverage results make it possible to assess the athlete's current condition and where to concentrate and adjust his future preparation.

Depending on the tasks of the study, dispersion analysis (ANOVA) and variation analysis, mathematical and statistical processing of results - SPSS version 19.

Respondents: 77 Students of Sofia University, a regular form of education from different faculties and majors. All students have the discipline "Sports" in the school curriculum and they have chosen to practice basketball. Students are divided into four groups - two experimental and two controllers in the following way: E1 - male (23 students), which is $29.9 \%$; E2 - women (16 students), which is $20.80 \%$, K1 - men (21 students), which is $27.3 \%$ and $\mathrm{K} 2$ - women (17 students), which is $22.10 \%$. 
Table 1. SPARQ test for basketball

\begin{tabular}{|l|l|l|l|l|}
\hline \multicolumn{2}{|l|}{ SPARQ test for basketball } & $\begin{array}{l}\text { Units of } \\
\text { measurement }\end{array}$ & $\begin{array}{l}\text { Measuring } \\
\text { accuracy }\end{array}$ & $\begin{array}{l}\text { Direction of } \\
\text { increase }\end{array}$ \\
\hline & TESTS & $\mathrm{cm}$ & 1 & + \\
\hline 1 & Standing Vertical Jump & $\mathrm{cm}$ & 1 & + \\
\hline 2 & Max Touch Jump & $\mathrm{s}$ & 0.1 & - \\
\hline 3 & $3 / 4$ Basket Court Sprint $-22,85 \mathrm{~m}$ & $\mathrm{~s}$ & 0.1 & - \\
\hline 4 & Lane Agility Drill & $\mathrm{cm}$ & 1 & + \\
\hline 5 & Kneeling Power Ball Throw: W-2kg/M-3kg & $\mathrm{n}$ & 0 & + \\
\hline 6 & Multi-Stage Hurdle & $\mathrm{cm}$ & 1 & + \\
\hline 7 & Flexibility & & & + \\
\hline
\end{tabular}

\section{ANALYSIS OF RESULTS}

Two methods for removing the index are used to examine the height of the bounce. The explosive force of the lower limbs was investigated in a jump from a place. The bounce is on two legs.

Jumping with maximum touch after stepping is a specific basketball test that measures the maximum touch height, range, bounce technique, and blasting power.

To determine the bounce, the average value between the results obtained in the two tests shall be reported.

A significant intragroup change $(F=56,525, p$ $=0,000)$ was observed in the bounce site analysis.

The analysis of the intergroup effects of the obtained values $(\mathrm{F}=50,663, \mathrm{p}=0,00)$ gives reason to note that there are statistically significant differences in the groups. The changes occurring in the E1 and E2 groups are positive and with a larger difference in input / output, but E1 and E2 cannot reach the K1 and $\mathrm{K} 2$ values that have a higher baseline (Figure 1).

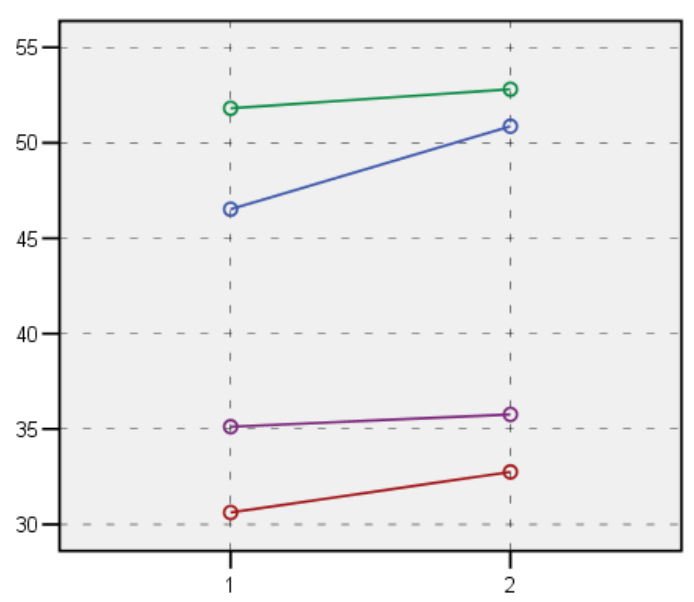

Figure 1. Standing Vertical Jump
The results of bounce with maximum touch and enhancement also showed significant change in groups $(\mathrm{F}=55,666, \mathrm{p}=0,000)$ and significant differences between groups $(\mathrm{F}=$ $39,225, p=0,000)$ It is important to note that the results of this analysis show an approximation between baseline levels of the study groups. Unlike a bounce from a place, the groups E1 and E2, which again have lower inputs, reach the level at the second reading of the $\mathrm{K} 1$ and $\mathrm{K} 2$ (Figure 2). This is reported as a positive result from the implementation of the methodology for improvement of the specific conditioning training.

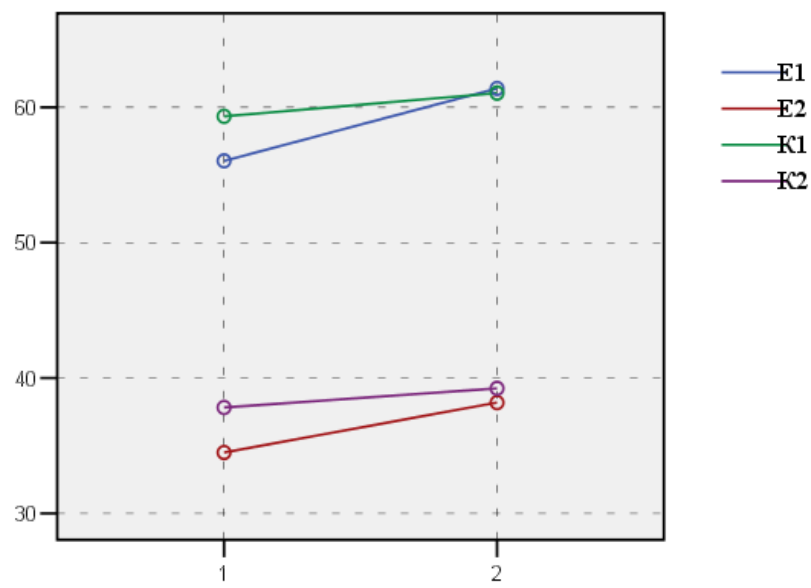

Figure 2. Max Touch Jump

In the mean bounce results, there was a significant change in the groups $(\mathrm{F}=88,466, \mathrm{p}$ $=0,000)$ and significant differences between the groups $(\mathrm{F}=48,123, \mathrm{p}=0,000)$ (Figure 3). The results between Standing Vertical Jump and Max Touch Jump are presented on Figure 4.

The measured values for speed indicators are two specific basketball tests. The first test is a sprint at a distance of $22.85 \mathrm{~m}$, which is the distance from the end line of the basketball field to the distant penalty line. It measures the linear speed. 

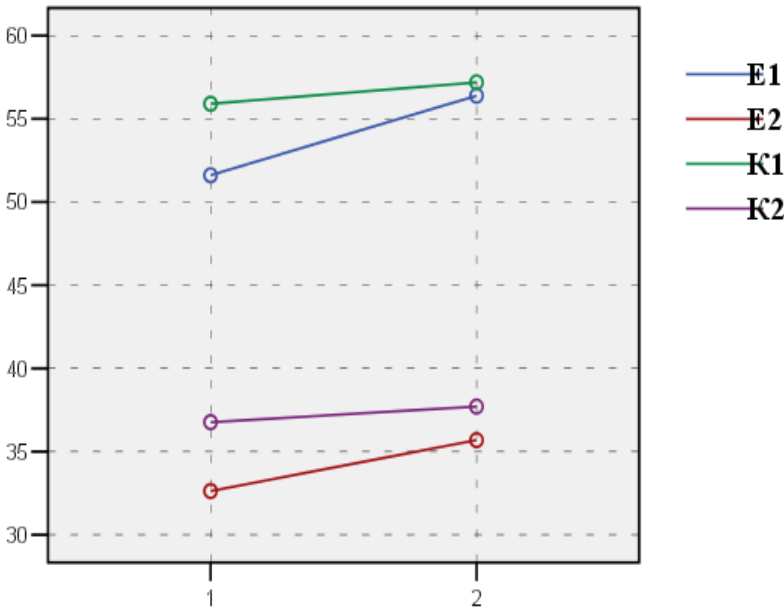

Figure 3. Jump - average value

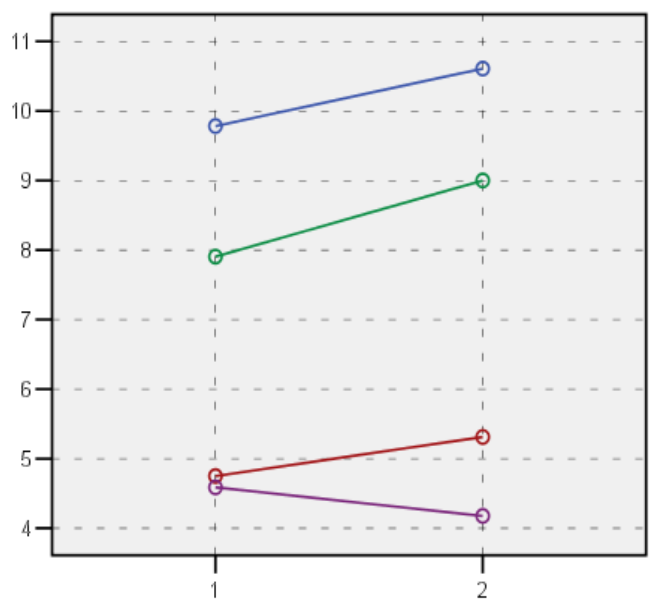

Figure 4. Jump - difference of values

The second test includes sprinting, defense movement (lateral sliding) and back-running. These elements are basic basketball skills performed without a ball. The distance is small (around the penalty area $-5.80 \times 4.90 \mathrm{~m}$ ), but basketball training is required. This test evaluates the speed, the ability to quickly change direction and coordination.

The analysis of the sprint results shows a significant change in the groups $(F=35,510, p$ $=0,000)$. In Figure 5, it can be seen that E1 and E2 at the entry level have lower K1 and $\mathrm{K} 2$ results, and at baseline, even in men, better values are observed in the second study. This is also evidenced by the inter-group analysis, which shows that there is a significant difference in the groups $(\mathrm{F}=52,631, \mathrm{p}=$ $0,000)$.

Regarding the results of the basketball-specific test it was found that the F-criterion values at time indicator were $(\mathrm{F}=86,138, \mathrm{p}=0,000)$, proving that there was a significant change in the groups.

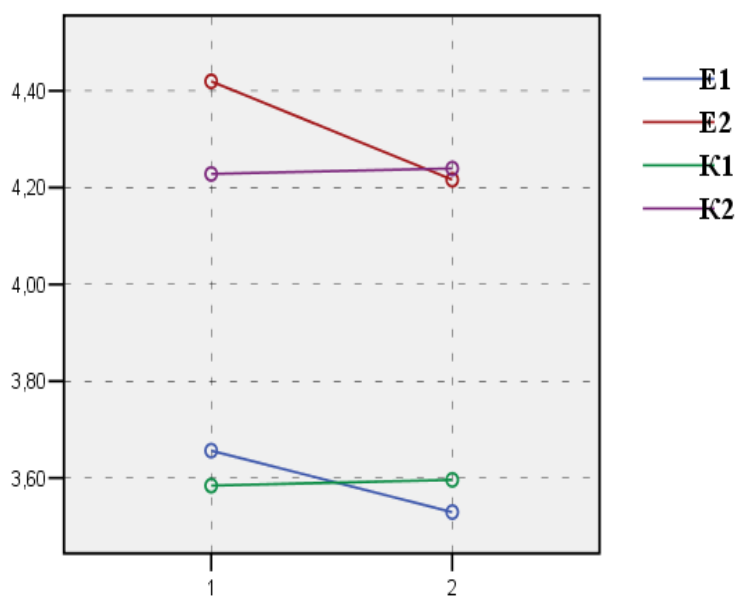

Figure 5. $3 / 4$ Basket Court Sprint $-22,85 \mathrm{~m}$

In the analysis of intergroup effects, the values are: $F=27,501, p=0,000$. Figure 6 clearly shows the better results achieved by experimental groups E1 and E2 relative to $\mathrm{K} 1$ and $\mathrm{K} 2$. In our opinion, this significant change is an effect of the applied experimental methodology for specific conditioning training in basketball training in the experimental groups.

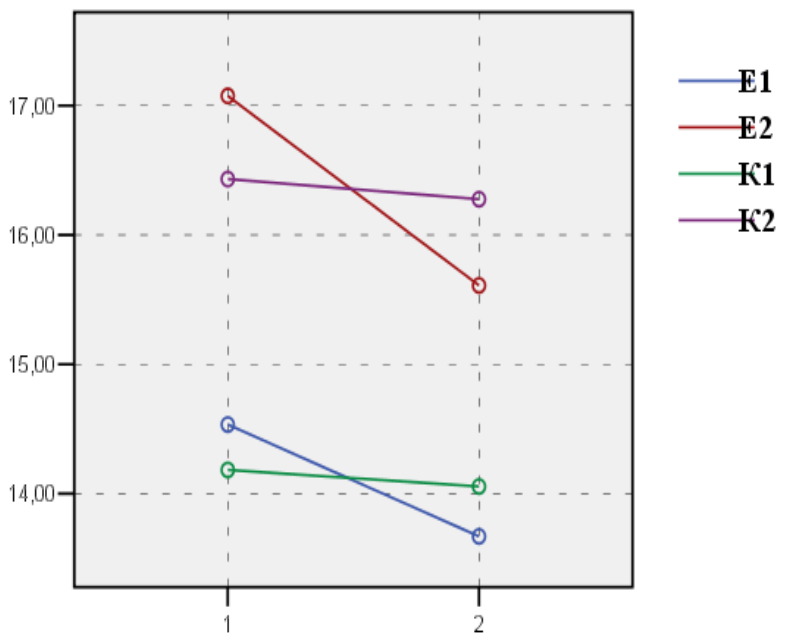

Figure 6. Lane Agility Drill

The analysis of the flexibility values (Figure 7) shows that there was a significant change in the groups $(\mathrm{F}=82,377, \mathrm{p}=0,000)$, but the difference between the groups was not statistically significant $(F=0,091, p=0,425)$. This is due to the close values of the indicators.

Figure 8 shows the differences in the values of throwing a medical ball. The analysis of the results shows a significant change in the groups and a significant difference between the groups. The values show that $\mathrm{F}=120,266, \mathrm{p}=$ 0,000 for an intragroup effect and $F=61,776$, $\mathrm{p}=0,000$ for the intergroup. 


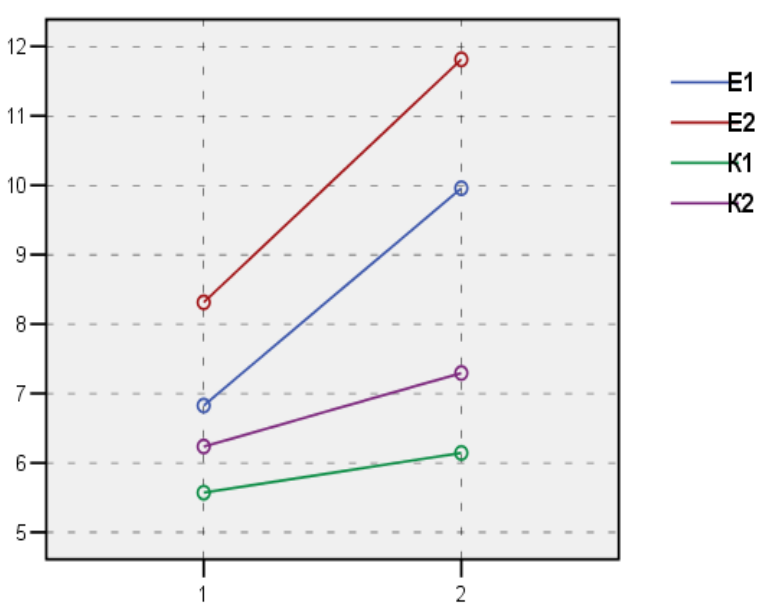

Figure 7. Flexibility

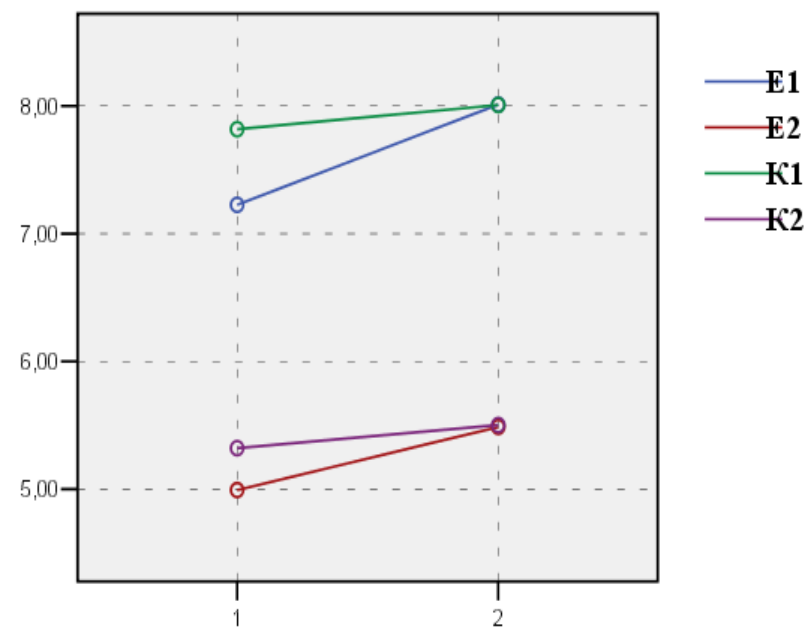

Figure 8. Kneeling Power Ball Throw

The test is carried out for 60 seconds, with the time being distributed as follows: 20 seconds of jumping, 20 seconds of resting and 20 seconds of jumping again. (Figures 9 and 10) The strength test determines the level of the jumping test in basketball.

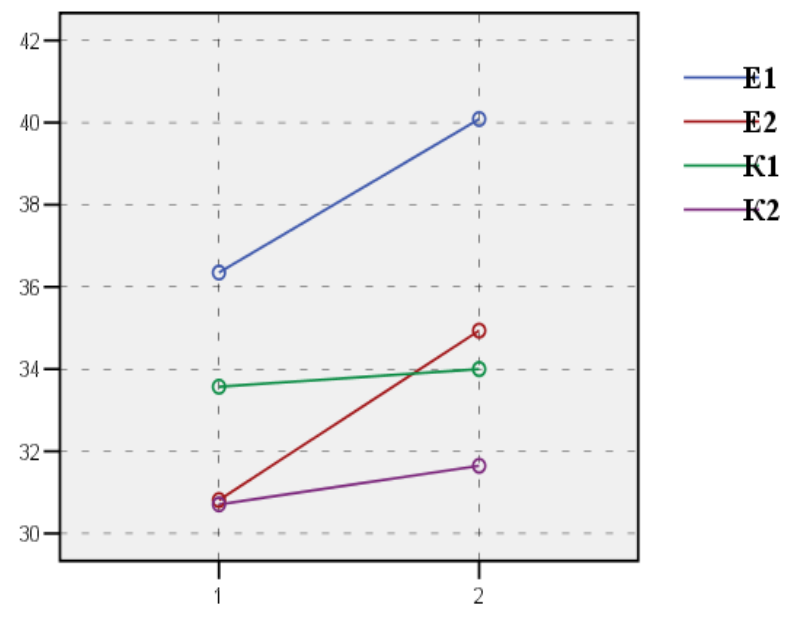

Figure 9. Multi-Stage Hurdle first 20s
The summary of 40 seconds of jumps gives us an idea of the strength of the lower limbs, agility, coordination, and the difference in the number of jumps made gives us an idea of the fatigue index.

The analysis of the multiple jumps shows a significant change in the groups and a significant difference between the groups. The $\mathrm{F}$ values are respectively $\mathrm{F}=186,504, \mathrm{p}=$ 0,000 and $F=10,021, p=0,000$

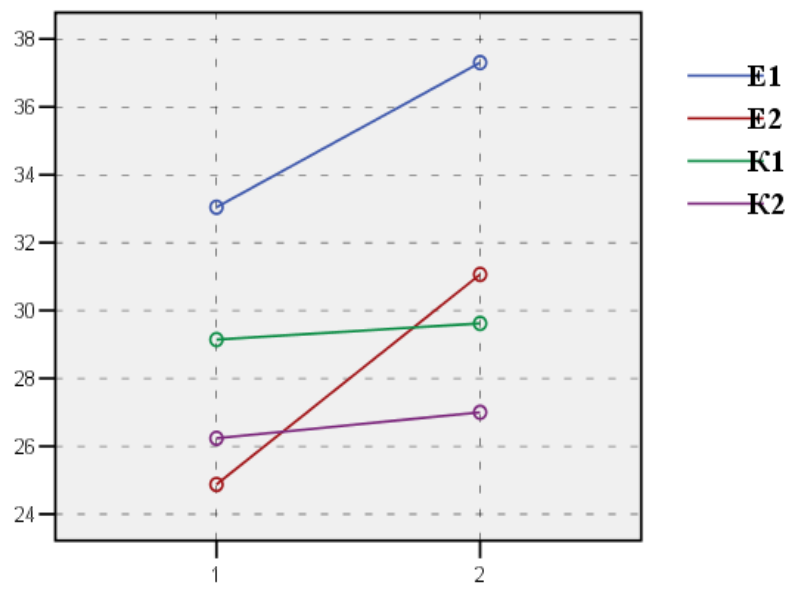

Figure 10. Multi-Stage Hurdle twenty 20s

\section{CONCLUSION}

There is a sensitive difference in blasting power, measured by bounce from place and with the maximum touch of the sexes, with pronounced superiority in men. This difference may be due to better coordination skills in men as a result of longer basketball training before entering the University.

There is no gender difference in the strength strength data measured by the multiple jumps test. Even the women in the experimental group at baseline surpass the men from the control. By this index the growth of the students from the experimental groups is higher than those of the control groups.

In terms of flexibility, there is again a greater increase in experimental groups, with women having the highest input and output data with the highest growth.

In the Sprint - a measure of speed, women's students in the experimental group have the greatest improvement as they have the lowest input data. In control groups the improvement is very small and it can be said that the students from these groups are on the same level. 
In summary, the purposeful methodology for improving the conditionality of basketball students is extremely important. It can be applied both in the individual preparation and in the basketball practice, regardless of gender. All this requires the search for new models for basketball training, including specialized conditioning training for students.

The efforts made and the results achieved in the experimental groups give encouraging signals for the correct methodology for preparation.

\section{REFERENCES}

1. Simeonova, T., Bancheva Y. and Klechkov, P., Comparative analysis of the physical and technical preparation of basketball for students from different universities. Scientific conference with international participation "Educational Technologies" (300 years since the birth of Jean Jacques Rousseau). Published in the yearbook of ShU. ISSN 1314-6769, Vol. XVI d, 2012.

2. Kasabova, L. Influence of Game Basketball on Physical Ability in Students of the University of National and World Economy. Collection "Modern Trends, Problems and Innovations in Physical Education and Sport in Higher Education". UNWE-press, ISBN 978-954-644-223-9, pp. 250-256, 2011.

3. Kasabova, L. and Dimitrov, A. Differences in the structure of motor skills of basketball players with different qualifications. Collection "Kinesiology 2002", "Boyka" press, V. Tarnovo, ISBN 954-9689-08-5, pp 227-230, 2002.

4. Ignatov, G. Verification of the Physical Preparedness of the Student Football Team of the Sofia University. 8th ISC, Department of Sports, SU "St. Kliment Ohridski ", "Modern Trends in Physical Education and Sports". "St. Kliment Ohridski" - press, S., ISSN 1314-2275, pp. 16-23, 2016.
PELTEKOVA I.

5. Ignatov, G. and Atanasov, E. Control and assessment of the physical capabilities of the student football teams of the Sofia University and the National Sports Academy. 14-th international scientific and professional conference, Veles. Research in Kinesiology. International Journal of Kinesiology and Other Related Sciences. Vol. 45, 1/2017, ISSN 1857-7679 (print), ISSN 1857-8942 (online), pp. 45-48, 2017.

6. Dyakova, G., Peeva, P. and Bozhkova, A. Exploring the variability of physical qualities and morpho-functional indicators of students from the Thracian University. Sport and Science Magazine, extraordinary issue № 1, S., ISSN 1310-3393, pp. 587592, 2007.

7. Bozhkova, A. Investigation of the specific capacity of students from the specialized volleyball groups of non-specialized higher schools. Sport \& Science Magazine, Extraordinary Issue № 4, S., ISSN 13103393, pp. 100-108, 2008.

8. Bozhkova, A. Study of the variation of physical qualities and morpho-functional indicators of students in dental medicine. "St. Kliment Ohridski" - press, S., ISSN 1314-2275, pp. 7-15, 2012.

9. Bozhkova, A., G. Dyakova. Comparative analysis of motor abilities of female students from various higher schools. Sport \& Science, ISNN 1310-3393, Extra issue, Proceeding book, XVI ISC "Olympic Sport and Sport for all" \& VI ISC "Sport, Stress, Adaptation”, pp. 178-182, 2012.

10.Bozhova, A., Dyakova, G. and Arsova R. Effectiveness of some special strength training exercises in volleyball students. Sport \& Science Magazine, ISSN 13103303, extraordinary issue № 4 - Part II, S., pp. 198-204, 2010.

11.Tsankov, Ts. Speed-power training of teenage basketball players. NSA-press, S., ISBN 945-718-160-2, pp. 0-111, 2005. 